\title{
Microsatellite instability in gastric MALT lymphoma
}

\author{
Eva Niv ${ }^{1,2}$, Yonit Bomstein ${ }^{2}$, Joelle Bernheim ${ }^{3,4}$ and Michael Lishner ${ }^{1,2,4}$ \\ ${ }^{1}$ Department of Medicine; ${ }^{2}$ Oncogenetic Laboratory; ${ }^{3}$ Department of Pathology, Meir Hospital, Kfar-Saba, \\ Israel and ${ }^{4}$ Sackler Faculty of Medicine, Tel-Aviv University, Tel-Aviv, Israel
}

\begin{abstract}
The role of microsatellite instability and defects in DNA mismatch repair mechanism in the pathogenesis of gastric lymphoma of mucosa-associated lymphoid tissue (MALT) type is still controversial, as both negative and positive findings have been reported. This may be explained mainly by arbitrary selection of the tested loci, the use of various techniques of microsatellite instability analysis and by different definitions of replication error positive phenotype. The aim of our study was to evaluate the instability at selected microsatellite markers using the GeneScan Analysis Software. DNA from paraffin-embedded tissue blocks of 13 previously untreated patients with localized gastric MALT lymphoma was extracted. Five microsatellite markers, which are located in hMSH2, hMLH1, P16, APC and MLL loci, were selected from the genetic database. We found genetic instability in tumors of 9/13 patients with gastric MALT lymphoma (69\%). Seven of them had replication-error-positive phenotype (54\%). Microsatellite instability was found in $39 \%$ of the samples in the MLL locus, $39 \%$ in the APC, $46 \%$ in the P16, 23\% in the $h M L H 1$ and none in the $h M S H 2$. This study demonstrates that microsatellite instability has more prominent role in pathogenesis of gastric MALT Iymphoma than reported to date. We suggest that microsatellite instability should be analyzed with markers adjacent to chromosomal loci that are involved in lymphomas. Our findings support the 'Real Common Target genes' theory of high rate of microsatellite instability in specific genes, which are associated with related tumors.
\end{abstract}

Modern Pathology (2004) 17, 1407-1413, advance online publication, 23 July 2004; doi:10.1038/modpathol.3800207

Keywords: microsatellite instability; genetic instability; loss of heterozygosity; mucosa-associated lymphoid tissue lymphoma; replication-error-positive phenotype

Lymphomas of mucosa-associated lymphoid tissue (MALT lymphomas) are extranodal low-grade B-cell tumors, which arise mainly in the stomach, but also in the thyroid, salivary glands, lungs and other organs. The pathogenesis of gastric MALT lymphomas may be related to local immune response to Helicobacter pylori, which is found in more than $90 \%$ of the cases. ${ }^{1-3}$ However, the exact role of the $H$. pylori in lymphomagenesis is unknown.

From the molecular aspect, the rearrangements of $b c l-1, b c l-2$ and c-myc genes, characterizing nodal lymphoma, are not found in gastric MALT lymphoma. Several genetic aberrations were found to be associated with MALT lymphoma including trisomy 3 , trisomy 18, $\mathrm{t}(11 ; 18)$ (q21;q21) that occur frequently in low-grade MALT lymphoma, as well as mutations in p53 (17p13) and P16 deletion (9p21), linked to high-grade transformation. ${ }^{2,4-9}$

Correspondence: Professor M Lishner, MD, Department of Medicine, Meir Hospital, Sapir Medical Center, Kfar-Saba, Israel. E-mail: michael2@clalit.org.il

Received 22 January 2004; revised 14 May 2004; accepted 17 May 2004; published online 23 July 2004
Recently, a possible role for defects in DNA mismatch repair mechanism in the pathogenesis of different malignancies, including MALT lymphoma, has been suggested. ${ }^{10-14}$ Defects in the DNA repair are reflected by DNA microsatellite instability. Microsatellites are short repeat sequences dispersed throughout the genome. They are composed of mono-, di-, tri- or tetranucleotide repeats. Microsatellites are highly unstable, that is, the number of repeat units tends to change due to slippage errors during DNA replications. These errors are supposed to be corrected by DNA repair enzymes, just like errors in any part of the genome. Cells with alteration in DNA mismatch repair enzymes are not able to repair errors during DNA replication, demonstrating replication-error-positive phenotype positivity. This instability makes microsatellites the best markers of replication-error-positive phenotype. Amplification of microsatellites by polymerase chain reaction (PCR) from the genome of malignant cells as compared to normal cells, enables to find mutations inside the microsatellites and to determine a malfunction of DNA mismatch repair enzymes. ${ }^{15,16}$ 
Microsatellite instability has been found in up to $90 \%$ of tumors of the hereditary nonpolyposis colorectal cancer because of germline mutations and further damage to the second allele within the specific mismatch repair genes hMSH1, hMLH2 and $h P M S 2 .{ }^{15-17}$ Microsatellite instability is also a distinctive feature in nearly $15-20 \%$ of sporadic colorectal tumors. ${ }^{18-20}$ Replication-error-positive phenotype has been detected recently in other solid tumors ${ }^{21-24}$ and in various lymphomas and leukemias. ${ }^{25-30}$

The involvement of microsatellite instability in the pathogenesis of gastric lymphoma of MALT type is controversial, as both negative and positive findings were reported. ${ }^{4-6,10,11,13,31,32}$ However, the microsatellite loci examined in these studies were randomly selected and the microsatellite analysis was performed by various methods. We aimed to evaluate the instability at microsatellite markers adjacent to chromosomal loci that are known to be involved in development of hematological malignancies (particularly of lymphomas) or at loci that encode DNA mismatch repair enzymes. We used modern and accurate GeneScan Analysis Software for this purpose.

\section{Materials and methods}

\section{Case Selection}

Archival specimens of consecutive patients with gastric MALT lymphoma tissue of last 3 years were obtained from the Pathology Department of Meir Hospital. All specimens of which enough DNA could be extracted from both normal and malignant gastric tissues were evaluated in this study. Gastric MALT lymphoma was diagnosed by histological criteria, immunophenotyping and the presence of Bcell monoclonality. Specimens of 13 patients met the predefined criteria. The charts of these patients were obtained and demographic, laboratory and clinical data were collected.

\section{DNA Collection and Processing}

Two paraffin-embedded tissue blocks of each patient were selected: lymphoma tissue and normal tissue. Sections of $5 \mu \mathrm{m}$ thickness of each block were cut and mounted on microscope slides. Hematoxylin and eosin ( $\mathrm{H}$ and $\mathrm{E}$ )-stained slides were prepared and used to demarcate areas containing cancer and normal cells. Corresponding regions were marked on unstained slides, and microdissection was performed.

DNA from the paraffin-embedded tissue sections was extracted using Puregene manufacturer's kit (Gentra, Minneapolis, MN, USA) according to instructions, by digestion with proteinase K, 'salting out' method and precipitation in ethanol. All the abnormal sections, microdissected if needed, contained more than $90 \%$ of malignant tissue.

\section{Microsatellite Marker Analysis}

Primer sequences at five different loci were selected from the Genome Database (Table 1): APC, MLL, hMLH1, P16 and hMSH2. The loci were selected on the basis of their known involvement in different hematological malignancies or DNA mismatch repair mechanism. $P 16$ is a tumor suppressor gene, which is located on 9p21 and encodes an inhibitor of cyclin-dependent kinase 4 (CDK4). Binding of the product of P16 to CDK4 usually prevents progression through the cell cycle. Alteration of the P16 gene, like deletions, hypermethylation and mutations, were reported in MALT lymphoma. ${ }^{2,12,14}$ Translocations in MLL (11q23) are common in different kinds of hematological malignancies, especially in AML and ALL. APC, located on 5q22-23, is involved mainly in colorectal cancer. The DNA mismatch repair enzymes hMLH1 and hMSH2 are involved in tumorigenesis of various malignancies.

The microsatellites within or closely located to these loci were amplified by PCR. One end of each primer was synthesized and labeled by FAM (Mycrosynth, Balgach, Switzerland) and the opposite end was synthesized by Sigma-Genosys (Cambridgeshire, UK). Microsatellite loci were amplified by PCR using Biometra Thermocycler (Whatman, Göttingen, Germany) in $15 \mu \mathrm{l}$ volume. The PCR mixture consisted of $1 \times$ PCR buffer $(10 \mathrm{mM}$ Tris$\mathrm{HCl}, \mathrm{pH}$ 8.3, $50 \mathrm{mM} \mathrm{KCl}, 1.5 \mathrm{mM} \mathrm{MgCl}_{2}$ ), $0.2 \mathrm{mM}$ of each dNTP (Roche, Mannheim, Germany), 6 pmol of each primer and $1.5 \mathrm{U}$ of Taq polymerase (Sigma, MO, USA).

Table 1 Microsatellite markers

\begin{tabular}{|c|c|c|c|c|}
\hline BAT26 & $2 \mathrm{p} 22-$ & $(\mathrm{A})_{26}$ & hMSH2, intron 5 & $\begin{array}{l}\text { F-FAM TGACTACTTTTGACTTCAGCC } \\
\text { R AACCATTCAACATTTTTAACCC }\end{array}$ \\
\hline D3S1611 & $3 p 24.2-p 22$ & $(\mathrm{CA})_{14}$ & $h M L H 1$, intron 12 & $\begin{array}{l}\text { F-FAM CCCCAAGGCTGCACTT } \\
\text { R AGCTGAGACTACAGGCATTTG }\end{array}$ \\
\hline D5S346 & $5 q 22-q 23$ & $(\mathrm{CA})_{26}$ & $A P C$, distance $30-70 \mathrm{~kb}$ & $\begin{array}{l}\text { F-FAM ACTCACTCTAGTGATAAATCG } \\
\text { R AGCAGATAAGACAGTATTACTAGTT }\end{array}$ \\
\hline D9S171 & $9 \mathrm{p} 21$ & $(\mathrm{CA})_{14}$ & P16 & $\begin{array}{l}\text { F-FAM GCTAAGTGAACCTCATCTCTGTCT } \\
\text { R GAGATCCTATTTTTCTTGGGGC }\end{array}$ \\
\hline D11S614 & $11 q 23$ & $(\mathrm{~A})_{13}(\mathrm{GAA})_{5}$ & $M L L$ intron 6 & $\begin{array}{l}\text { F-FAM CGCTGGTAATCCCAACACTT } \\
\text { R ACCTGGGACTACACGCAACT }\end{array}$ \\
\hline
\end{tabular}


PCR mixtures were subjected to 36 cycles of PCR with automated temperature cycling program as follows: denaturation at $94^{\circ} \mathrm{C}$ for $30 \mathrm{~s}$, annealing at $55^{\circ} \mathrm{C}$ for all primers except $\mathrm{P} 16\left(57.5^{\circ} \mathrm{C}\right)$ for $30 \mathrm{~s}$ and elongation at $72^{\circ} \mathrm{C}$ for $30 \mathrm{~s}$. Amplification was concluded with extension at $72^{\circ} \mathrm{C}$ for $30 \mathrm{~min}$ to promote an addition of A base to all the PCR products by Taq DNA polymerase to the $3^{\prime}$ end of DNA.

Fluorescent PCR products were subjected to electrophoresis on denaturing polyacrylamide gel and fractionated by Automated Fluorescent DNA Sequencer (ABI 377, PE Biosystems). The data were processed using the GeneScan Analysis Software (Perkin-Elmer, Foster City, CA, USA).
Microsatellite instability was defined as a change of length due to either insertion or deletion of repeating units in a microsatellite within tumor cells as compared to normal cells. ${ }^{15,16}$ The change presented as novel peak/s in tumor tissue DNA differing in size and location from normal tissue DNA. Figure 1 presents microsatellite stability as compared with microsatellite instability in Figure 2. Loss of heterozygosity or allelic imbalance were defined as a loss of one of the pre-existing alleles in the tumor as compared to normal tissue. In this situation, one cannot easily distinguish whether it represents true loss of heterozygosity or microsatellite instability in which the shifted allele has comigrated with the

\section{a Normal cells}

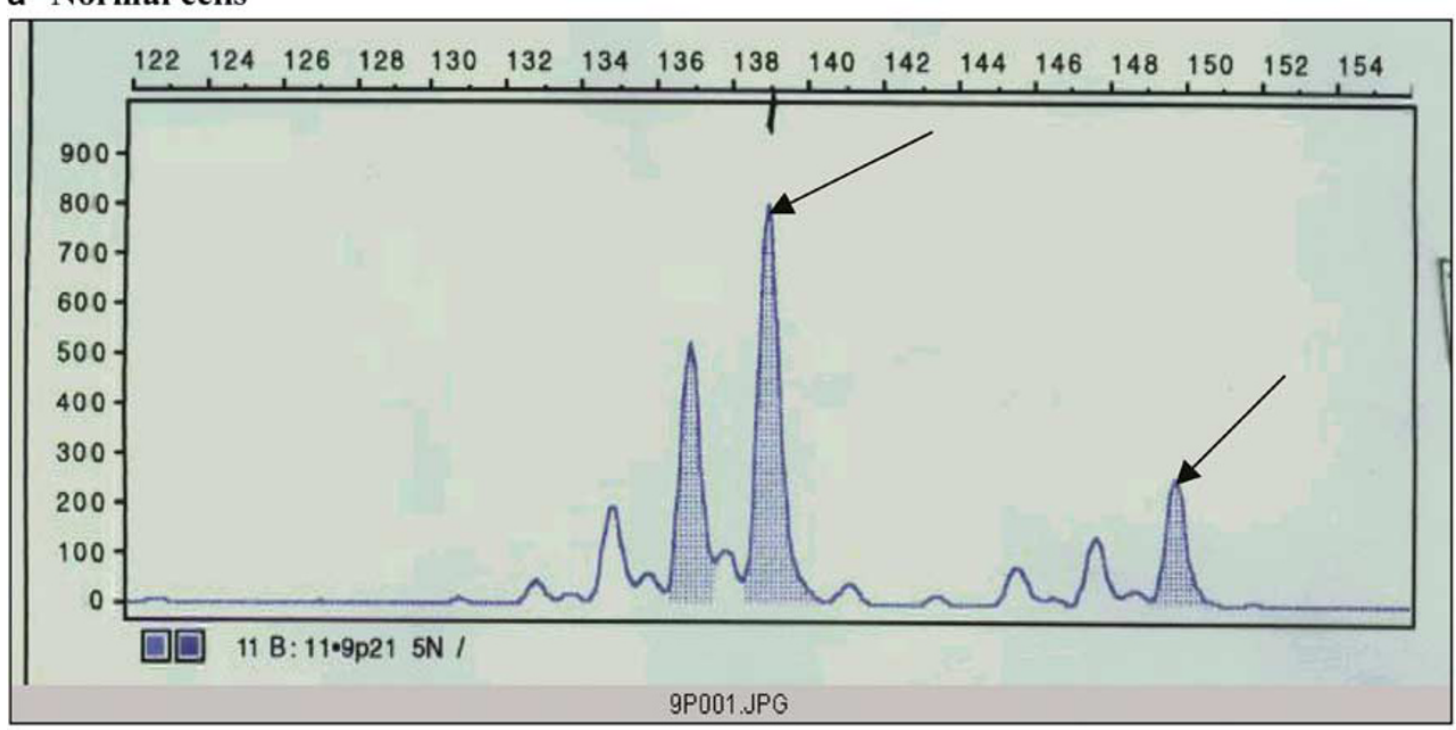

\section{b Malignant cells}

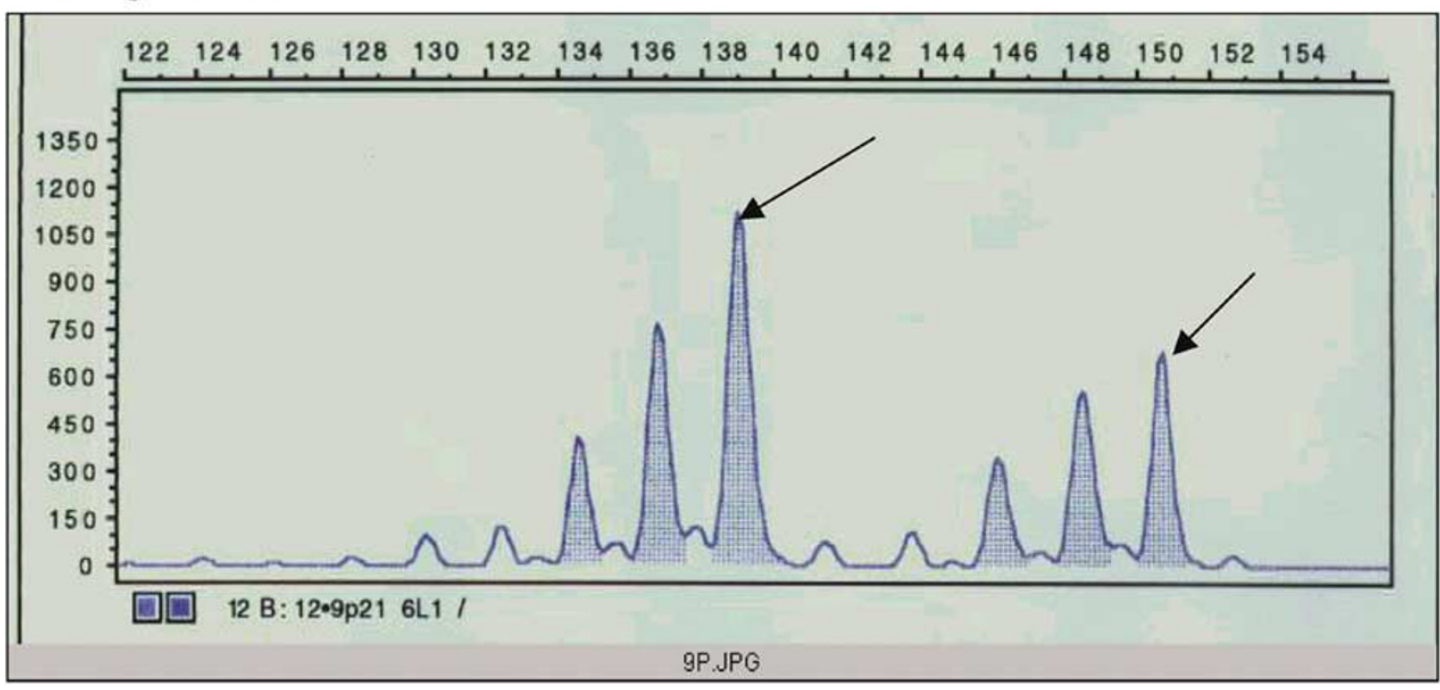

Figure 1 Representative allelic profile of microsatellite stability at $P 16$ locus. Horizontal—base pairs scale, vertical-fluorescence scale. Both in normal (a) and malignant (b) cells, the two major peaks are 139 and 150 base pairs long representing the two alleles of this microsatellite. 


\section{a Normal cells}

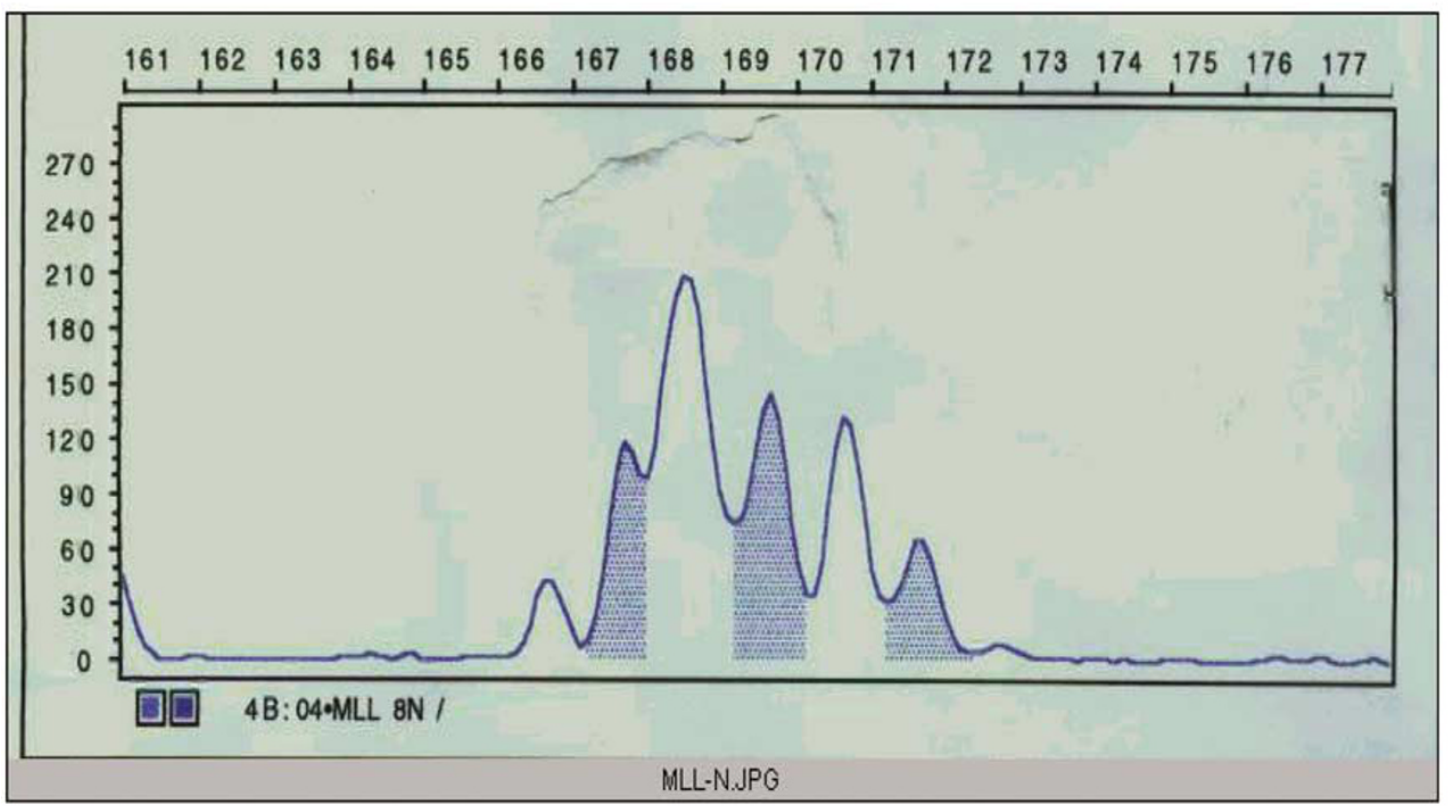

b Malignant cells

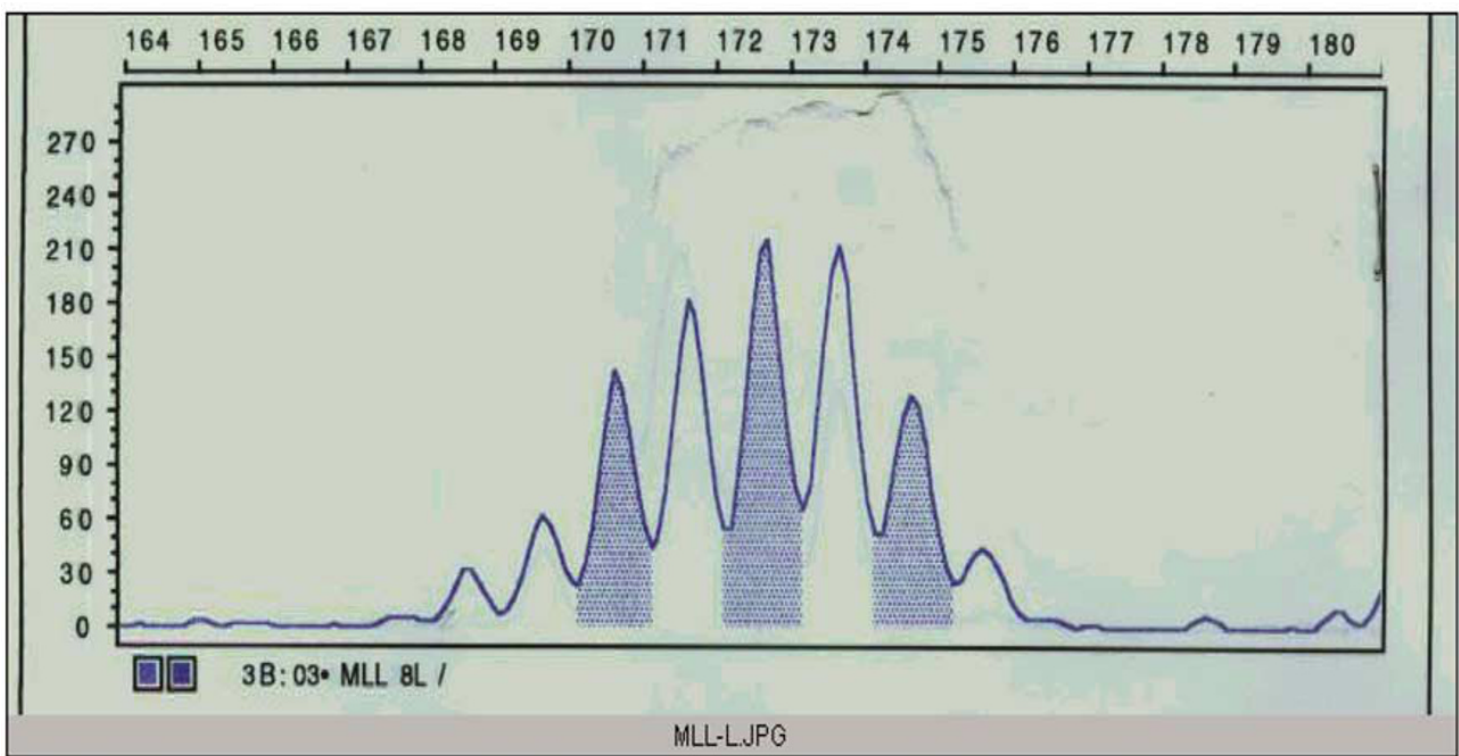

Figure 2 Representative allelic profile of microsatellite instability at $M L L$ locus. Horizontal—base pairs scale, vertical—fluorescence scale. The alleles of this microsatellite have different lengths in normal (a) and malignant cells (b).

remaining wild-type allele. We defined these cases as loss of heterozygosity introducing a possible bias in favor of group with loss of heterozygosity.

According to accepted criteria we defined a patient with replication-error-positive phenotype if he had at least two microsatellite instabilities at different loci. ${ }^{15}$ A patient who had at least one microsatellite instability and at least one loss of heterozygosity was defined as having genetic in- stability. The group with genetic instability also included patients with replication-error-positive phenotypes.

\section{Statistical Analysis}

Standard descriptive statistics, including means, standard deviations, ranges and frequency calculations were used to characterize the study group. For 
comparisons, a $\chi^{2}$ with two-sided type I error of 0.05 was used to assess statistical significance.

\section{Results}

Pathologic specimens of 13 patients with previously untreated gastric MALT lymphoma were obtained. In all cases, MALT lymphoma was localized and did not pass muscularis propria of the stomach. None demonstrated a transformation to high-grade large B-cell lymphoma. The mean age of the patients at diagnosis was 63.3 (range 44-79) years. Seven of 13 patients were women. No patient had prior treatment with antibiotics or chemotherapy.

Table 2 presents the results of microsatellite markers' analysis in the specimens of the study group. Tumors of nine patients (M1, M4, M5, M6, M8, M9, M11, M12, M13) had a genetic instability (69\%). Seven of them (M1, M4, M5, M6, M8, M11, M13) had replication-error-positive phenotype $(54 \%)$. It should be stressed that in some loci, testing of microsatellite instability failed due to technical reasons. These loci were considered as stable, which may have introduced some bias into our results.

Table 3 focuses on the frequency of microsatellite instability and genetic instability in each microsatellite locus. Microsatellite instability was found in $39 \%$ of the samples in the MLL locus, $39 \%$ in the $A P C$ locus, $46 \%$ in the $P 16$ locus and $23 \%$ in the hMLH1 locus. The hMSH2 locus did not demonstrate any instability. Genetic instability was demon- strated in $46 \%$ of samples in the $M L L$ locus, $46 \%$ of the samples in the $A P C$ locus, $46 \%$ in the $P 16$ locus, $39 \%$ in the $h M L H 1$ locus and in only $15 \%$ of the samples in the hMSH2 locus.

\section{Discussion}

We found genetic instability in tumors of 9/13 (69\%) of previously untreated patients with gastric MALT lymphoma. Seven of them (54\%) were found to have replication-error-positive phenotype. The microsatellite's analysis was performed in selected genetic loci that are known to be involved in the development of hematologic malignancies or those that encode DNA mismatch repair enzymes. These results were obtained by GeneScan, which is modern and precise method of microsatellite's analysis.

Our results support previous reports about the significant role of defects in DNA mismatch repair mechanism in the pathogenesis of gastric MALT lymphoma. ${ }^{10,11}$ Peng et al $^{11}$ detected replicationerror-positive phenotype in tumors of 21/40 (52.5\%) patients with gastric MALT lymphomas. Chong et $a l^{10}$ study also suggested a high frequency of microsatellite instability. They contradict the results of other studies that reported a negligible role of microsatellite instability in gastric MALT lymphoma tumorigenesis..$^{6,31,32}$

There are a few explanations for these conflicting results. The most important variable seems to be the choice of different genetic loci for microsatellite

Table 2 Microsatellite analysis in the specimens of the study group

\begin{tabular}{lllll}
\hline & MLL & P16 & hMSH2 & APLH1 \\
\hline M1 & LOH & MSI & Stable & MSI \\
M2 & Stable & Stable & Stable & LOH \\
M3 & LOH & Stable & Stable & Stable \\
M4 & MSI & Stable & Stable & MSI \\
M5 & MSI & Stable & LOH & Stable \\
M6 & No data & MSI & No data & No data \\
M7 & No data & Stable & No data & MSI \\
M8 & MSI & MSI & Stable & Stable \\
M9 & No data & MSI & LOH & Nata \\
M10 & Stable & Stable & SOH \\
M11 & MSI & Stable & Stable & No data \\
M12 & Stable & MSI & Stable & Stable \\
M13 & MSI & MSI & No data & Stable \\
& & & Stable \\
\hline
\end{tabular}

MSI = microsatellite instability; $\mathrm{LOH}=$ loss of heterozygosity.

Table 3 Frequency of microsatellite and genetic instability at different loci

\begin{tabular}{|c|c|c|c|c|c|}
\hline & $M L L$ & $P 16$ & hMSH2 & $h M L H 1$ & $A P C$ \\
\hline MSI & $5 / 13(39 \%)$ & $6 / 13(46 \%)$ & 0/13 (0\%) & $3 / 13(23 \%)$ & $5 / 13(39 \%)$ \\
\hline Genetic instability & $6 / 13(46 \%)$ & $6 / 13(46 \%)$ & $2 / 13(15 \%)$ & $5 / 13(39 \%)$ & $6 / 13(46 \%)$ \\
\hline
\end{tabular}

MSI $=$ microsatellite instability. 
instability analysis. Most of the previous studies of MALT lymphoma (both with high and low reported rates of microsatellite instability) evaluated microsatellite instability in randomly selected loci, while we analyzed carefully selected loci, which may be relevant to tumorigenesis or mismatch repair mechanism. Also, the methodology used to analyze microsatellite instability is very important. In most previous studies, microsatellite instability analysis was based on electrophoresis on gel and not on GeneScan technique, that is considered to be the most accurate method. Finally, PCR is a very sensitive technique and it is important to obtain reproducible results by confirming the positive results as was done in our study.

The concept that microsatellite instability is more common in some genetic loci than in other is not new. In 1998, the National Cancer Institute published a workshop on microsatellite instability in colorectal cancer and a panel of few genetic loci was selected for the analysis of microsatellite instability out of few hundreds. ${ }^{15}$ The workshop recommended to compose an individual panel of the selected loci for each tumor, but this recommendation was not adopted in further studies. Actually, most studies of different tumors analyzed arbitrary selected genetic loci for microsatellite instability with wide variation in the reported results.

Recently, the 'Real Common Target genes' model was proposed. ${ }^{33-36}$ According to this model, sets of specific genes with a high rate of mutations in different mismatch repair-deficient human cancers were identified. Mutations in microsatellites inside these Real Common Target genes, which promote tumor cell growth, are assumed to be the driving force during microsatellite instability carcinogenesis. Mutations in microsatellites of these genes were found more frequently than in microsatellites of genes without involvement in malignant transformation (ByStander genes). So far, this model was suggested only for colorectal, gastric and endometrial carcinomas. In order to construct such models for other tumors, data regarding microsatellite instability in different genetic loci of different tumors, including MALT lymphoma, should be collected. We believe that our study may contribute to the identification of Real Common Target genes for MALT lymphoma. However, studies of larger groups with analysis of multiple meticulously selected loci are needed.

An interesting finding was the similar frequency of microsatellite and genetic instability in various loci (Table 3), except for hMSH2. MSH2 is one of the DNA mismatch repair enzymes and is unstable in various tumors. However, we show here that it is stable in MALT lymphoma. Another interesting finding was the high rate of instability in $A P C$, which is known to be unstable mainly in colorectal tumor. Previous studies found both low and high rate of instability of APC in gastric MALT lymphomas. ${ }^{6,9}$ We assume that this contradiction is related to the long length of $A P C$ locus with abundance of various microsatellites. Each of the previous studies tested different microsatellites within the APC locus and consequenly the results varied.

In conclusion, we found a high rate of microsatellite instability in selected loci in gastric MALT lymphoma. We suggest that DNA mismatch repair mechanism malfunction may have an important role in the pathogenesis of this tumor.

\section{References}

1 Isaacson PG. Primary gastric lymphoma. Pathol Oncol Res 1996;2:5-10.

2 Du MQ, Isaaccson PG. Gastric MALT lymphoma: from aetiology to treatment. Lancet Oncol 2002;3:97-104.

3 Eidt S, Stolte M, Fischer R. Helicobacter pylori gastritis and primary gastric non-Hodgkin's lymphomas. J Clin Pathol 1994;47:436-439.

4 Skacel M, Paris PL, Pettay JD, et al. Diffuse large B-cell lymphoma of the stomach: assessment of microsatellite instability, allelic imbalance and trisomy of chromosomes 3, 12 and 18. Diagn Mol Pathol 2002;11:75-82.

5 Starostik P, Greiner A, Schultz A, et al. Genetic aberrations common in gastric high-grade large B-cell lymphoma. Blood 2000;95:1180-1187.

6 Starostik P, Greiner A, Schwartz S, et al. The role of microsatellite instability in gastric low- and high-grade lymphoma development. Am J Pathol 2002;157: 1129-1136.

7 Starostik P, Patzner J, Greiner A, et al. Gastric marginal zone B-cell lymphomas of MALT type develop along 2 distinct pathogenetic pathways. Blood 2002;99:3-9.

8 Liu H, Ye H, Dogan A, et al. T $(11 ; 18)(q 21 ; q 21)$ is associated with advanced mucosa-associated lymphoid tissue lymphoma that expresses nuclear BCL10. Br J Haematol 2003;120:97-100.

9 Calvert R, Randerson J, Evans P, et al. Genetic abnormalities during transition from Helicobacterpylori associated gastritis to low-grade MALT lymphoma. Lancet 1995;345:26-27.

10 Chong JM, Fukayama M, Hayashi Y, et al. Microsatellite instability and loss of heterozygosity in gastric lymphoma. Lab Invest 1997;77:639-645.

11 Peng H, Chen G, Du M, et al. Replication error phenotype and p53 gene mutation in lymphomas of mucosa-associated lymphoid tissue. Am J Pathol 1996;148:643-648.

12 Kim YS, Kim JS, Jung HC, et al. Regression of low-grade gastric mucosa-associated lymphoid tissue lymphoma after eradication of Helicobacter pylori: possible association with p16 hypermethylation. J Gastroenterol 2002;37:17-22.

13 Hiyama T, Haruma K, Kitadai Y, et al. Microsatellite instability at D18S61 is associated with no regression of gastric mucosa-associated lymphoid tissue lymphoma after Helicobacter pylori eradication. Oncol Rep 2001;8:293-297.

14 Neumeister P, Hoefler G, Beham-Schmid C, et al. Deletion analysis of the p16 tumor suppressor gene in gastrointestinal mucosa-associated lymphoid tissue lymphomas. Gastroenterology 1997;112:1871-1875.

15 Boland CR, Thibodeau SN, Hamilton SR, et al. A National Cancer Institute Workshop on microsatellite 
instability for cancer detection and familial predisposition: development of international criteria for the determination of microsatellite instability in colorectal cancer. Cancer Res 1998;58:5248-5257.

16 Dietmaier W, Wallinger S, Bocker T, et al. Diagnostic microsatellite instability: definition and correlation with mismatch repair protein expression. Cancer Res 1997;57:4749-4756.

17 Peltomaki P, Vasen HF. Mutations predisposing to hereditary nonpolyposis colorectal cancer: database and results of a collaborative study. The International Collaborative group on Hereditary Nonpolyposis Colorectal Cancer. Gastroenterology 1997;113:1146-1158.

18 Samowitz WS, Slattery ML, Potter JD, et al. BAT-26 and BAT-40 instability in colorectal adenomas and carcinomas and germline polymorphism. Am J Pathol 1999;154:1637-1641.

19 Toft NJ, Arends MJ. DNA mismatch repair and colorectal cancer. J Pathol 1998;185:123-129.

20 Stone JG, Tomlinson IPM, Houlson RS. Optimizing methods for determining RER status in colorectal cancers. Cancer Lett 2000;149:15-20.

21 Arzimanoglou II, Gilbert F, Barber HRK. Microsatellite instability in human solid tumors. Cancer 1998;82: 1808-1820.

22 Leach FS, Koh M, Sharma K, et al. Mismatch repair gene mutations in renal cell carcinoma. Cancer Biol Ther 2002;1:530-536.

23 Steiner G, Reinschmidt G, Muller SC. Molecular genetic diagnosis of de novo and recurrent bladder cancer. Electrophoresis 1999;20:280-282.

$24 \mathrm{Xu} \mathrm{L}$, Chow J, Bonacum J, et al. Microsatellite instability at AAAG repeat sequences in respiratory tract cancers. Int J Cancer 2001;91:200-204.

25 Fulop Z, Csernus B, Timar B, et al. Microsatellite instability and hMLH1 promoter hypermethylation in Richter's transformation of chronic lymphocytic leukemia. Leukemia 2003;17:411-415.

26 Fundia A, Giere I, Larripa I, et al. Spontaneous breakage and fragile site expression in chronic lym- phocytic leukemia. Cancer Genet Cytogenet 1998;103: 144-148.

27 Gartenhaus R, Johns III MM, Wang P, et al. Mutator phenotype in a subset of chronic lymphocytic leukemia. Blood 1996;87:38-41.

28 Mark Z, Toren A, Amariglio N, et al. Instability of nucleotide repeats in Hodgkin's disease. Am J Hematol 1998;57:148-152.

29 Pabst T, Schwaller J, Bellomo MJ, et al. Frequent clonal loss of heterozygosity but scarcity of microsatellite instability at chromosomal breakpoint cluster regions in adult leukemias. Blood 1996;88: 1026-1034.

30 Volpe G, Gamberi B, Pastore C, et al. Analysis of microsatellite instability in chronic lymphoproliferative disorders. Ann Hematol 1996;72:67-71.

31 Furlan D, Bertoni F, Cerutti R, et al. Microsatellite instability in gastric MALT lymphomas and other associated neoplasms. Ann Oncol 1999;10 783-788.

32 Hoeve MA, Ferreira Mota SC, Schuuring E, et al. Frequent allelic imbalance but infrequent microsatellite instability in gastric lymphoma. Leukemia 1999; 13:1804-1811.

33 Duval A, Reperant M, Hamelin R. Comparative analysis of mutation frequency of coding and noncoding short mononucleotide repeats in mismatch repair deficient colorectal cancers. Oncogene 2002;21: 8062-8066.

34 Duval A, Hamelin R. Mutations at coding repeat sequences in mismatch repair-deficient human cancers: toward a new concept of target genes for instability. Cancer Res 2002;62:2447-2454.

35 Duval A, Hamelin R. Genetic instability in human mismatch repair deficient cancers. Ann Genet 2002; 45:71-75.

36 Woerner SM, Benner A, Sutter C, et al. Pathogenesis of DNA repair-deficient cancers: a statistical metaanalysis of putative Real Common Target genes. Oncogene 2003;22:2226-2235. 